\title{
Overwintering biology and morphological characteristics of the migratory locust, Locusta migratoria after outbreaks on Iheya Island, Japan
}

\author{
Masaaki YAMAGISHI ${ }^{1}$ and Seiji TANAKA ${ }^{2, *}$ \\ ${ }^{1}$ Plant Protection Center of Okinawa Prefecture; Naha, Okinawa 902-0072, Japan \\ ${ }^{2}$ Locust Research Laboratory, National Institute of Agrobiological Sciences at Ohwashi; Tsukuba, Ibaraki 305-8634, Japan \\ (Received 3 September 2008; Accepted 8 October 2008)
}

\begin{abstract}
Outbreaks of the migratory locust, Locusta migratoria L., occurred in 2005-2006 on Iheya Island, Okinawa, Japan. The present study was initiated in autumn 2006 to investigate the morphological characteristics of adult locusts after the outbreaks. Although most adults collected in the field showed morphometric traits typical of solitarious forms, a few adults were characterized by dark body coloration, a concave pronotum, relatively small $\mathrm{F} / \mathrm{C}$ ratios and large E/F ratios, often recorded in outbreaks. Locusts were sampled every month from October 2006 to March 2007 to determine the status of ovarian development. A few females with developing oocytes or eggs were always present in the samples, but most females had small oocytes until January. The mean time required to start oviposition after transfer to the laboratory $\left(12 \mathrm{~L} 12 \mathrm{D}\right.$ and $30^{\circ} \mathrm{C}$ ) was $16-18$ days in females collected in the autumn, but decreased significantly in those collected in late December onward. Eggs had a capacity for diapause at $20^{\circ} \mathrm{C}$, but not at 25 or $30^{\circ} \mathrm{C}$. The induction of diapause was influenced by the parental photoperiod. These results suggest that this locust overwinters mainly in the adult or egg stage on this island.
\end{abstract}

Key words: Locusta migratoria; overwintering; diapause; outbreaks; phase polyphenism

\section{INTRODUCTION}

Locusts are potentially the most destructive pest insect in the world. Outbreaks often occur and cause serious agricultural damage. In 2003-2005, several species of locusts underwent outbreaks in various areas, including Africa, Middle East Asia, India and China (Lecoq, 2005; Tanaka and Zhu, 2005). In 2005, the migratory locust, Locusta migratoria L. (Orthoptera: Acrididae) frequently swarmed on Iheya Island, Okinawa, Japan. According to local entomologists and residents (C. Moromizato and S. Saito, personal communications), the appearance of swarms was the subject of daily conversation on this island during the summer of that year, although no scientific data were reported. In and around sugarcane and paddy fields, numerous dark-colored nymphs were observed marching and insecticides were sprayed to control the populations. In the subtropical Ryukyu Islands of Okinawa Prefecture, this locust is not as common as the Bombay locust, Nomadacris succincta, but occasional outbreaks occur on some islands, such as Kita- and Minami-Daito Islands (Ito and Yamagishi, 1976).

The locust populations of L. migratoria on Iheya Island were much reduced in size in 2006, but still numerous locusts were present in the summer and dark-colored nymphs were seen marching around sugarcane fields in September (S. Saito, personal communications). One of the authors (M. Yamagishi) visited the island on 11 October 2006 and found that the populations were relatively large and consisted mostly of adults. During the present study, we made several trips to the island from October 2006 to March 2007 and collected locusts to examine their morphological characteristics in relation to phase polyphenism. One of the purposes of this paper is to report the results of that survey.

The present study also investigated the winter biology of L. migratoria on this island. Some developmental traits of Okinawa populations of this

\footnotetext{
* To whom correspondence should be addressed at: E-mail: stanaka@affrc.go.jp
} DOI: $10.1303 / \mathrm{aez} .2009 .165$ 
locust have been studied in the laboratory (Tanaka, H., 1994; Tanaka, S., 1994) and it has been suggested that this locust overwinters at various stages, including eggs, nymphs and adults; however, few empirical data are available about the winter biology of this species in the subtropical region in Japan. This lack of information might partly be due to the difficulty of obtaining enough locusts for experiments during the winter. The abundance of adults in autumn 2006 gave an impetus to study the winter biology of this locust.

\section{MATERIALS AND METHODS}

Collection of insects and pre-ovipositional period. Iheya Island is located at $27.1^{\circ} \mathrm{N}$ and $128.0^{\circ} \mathrm{E}$ and mean monthly air temperature ranges from 15.1 to $27.6^{\circ} \mathrm{C}$, with an annual mean of $21.3^{\circ} \mathrm{C}$ (Fig. 1). Locusts were collected in and around sugarcane and paddy fields every month from October 2006 through March 2007. For comparison, sampling was also made on September 24-25, 2008 when the locust populations of both L. migratoria and $N$. succincta were considerably smaller. One to four people searched for 2-10 h each time and locusts were caught with an insect net or by hands. The abundance of locust adults was roughly estimated by counting the number of adults per ca. $25 \mathrm{~m}^{2}$ on 19 November 2006. Collected locusts held together in large nylon-screened cages $(30 \times$ $30 \times 45 \mathrm{~cm})$ in the field were individually wrapped in tissue paper for shipment. Some female locusts were frozen for observations of ovarian development and the rest were sent together with males to the National Institute of Agrobiological Sciences at Ohwashi (NIASO) within 1 or 2 days after collection. At NIASO, each female was paired with a male at $30^{\circ} \mathrm{C}$ and a $12 \mathrm{~L} 12 \mathrm{D}$ photoperiod to measure the time to ovipositing, defined as the preovipositional period. All males were removed from the cages after the females started oviposition. Locusts were fed grass (Bromus catharticus) and wheat bran, and allowed to lay egg pods into moist sand in plastic caps (volume, $360 \mathrm{ml}$ ).

Measurements of body dimensions. Head width (C), hind femur length (F) and forewing length (E) of adult locusts were measured with digital calipers to determine the classical morphometric ratios, F/C and E/F ratios (Dirsh, 1953), to evaluate their phase status. Maximum body length

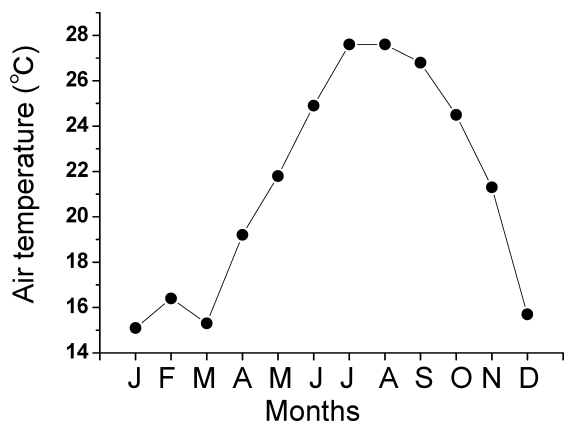

Fig. 1. Monthly mean air temperatures on Iheya Island in 2005 (Gakiya Dam Management Office of Okinawa Prefecture).

(MBL) from the head to the tip of wings was also measured. For comparison, the morphometric ratios of other populations at outbreak and recession times were cited. The data for Kita- and MinamiDaito Island populations were cited from Ito and Yamagishi (1976), those for Mage Island and Kagoshima populations from Tanaka (1987), and those for a northern Chinese population from Tanaka and Zhu (2005). Some ratios were calculated based on the data reported by Farrow and Colless (1980) for Madagascar, Philippine, Papua New Guinean, Mali, Central African and Australian populations. Unpublished data for the Isahaya population $(n=8$ in females and 25 in males in 2000 and $n=5$ in females and 9 in males in 2008; Y. Ikezaki and S. Tanaka, unpublished data), Kansai International Airport populations $(n=70$ in each sex; S. Tanaka, K. Maeno and M. Takeda, unpublished data) and Amami Ooshima population $(n=5$ in each sex; S. Tanaka, unpublished data) were also cited.

Measurements of ovarian development. Female adults collected each month in the field were frozen at $-40^{\circ} \mathrm{C}$ and sent to NIASO where they were dissected to observe the status of ovarian development. Each female was thawed and the ovary was removed with a pair of dissecting scissors. The number of ovarioles was determined by counting the ovarioles in one half pair of the ovary and doubling the value. From each ovary, the largest 6 oocytes or ovarian eggs were chosen and their lengths measured using an ocular micrometer under a binocular microscope. The mean oocyte length was then calculated for each individual.

Seasonal changes in diapause incidence and the effect of parental photoperiod on embryonic 
diapause. To investigate the propensity to enter diapause, female adults collected in October 2006January 2007 were reared under a 12L12D photoperiod and $30^{\circ} \mathrm{C}$, and the first and third egg pods deposited were incubated at $20^{\circ} \mathrm{C}$ to determine the incidence of diapause. Second egg pods deposited were used to test the effect of other temperatures on diapause incidences in preliminary experiments, which indicated that no eggs incubated at $25^{\circ} \mathrm{C}$ $(0 \% ; n=1,965)$ or $30^{\circ} \mathrm{C}(0 \% ; n>1,000)$ entered diapause (data not shown). At $20^{\circ} \mathrm{C}$, some eggs hatched within 60 days, but the rest remained unhatched for a long period of time because they either entered diapause or died. In the present experiment, all egg pods were transferred from 20 to $30^{\circ} \mathrm{C}$ on the 60th day after deposition and hatching was observed every day. After transfer to the higher temperature, live eggs hatched simultaneously from the 9 th to 12 th days. All egg pods were dissected to count the number of dead eggs after hatching ceased. Eggs hatching within 60 days of deposition were regarded as non-diapause individuals and those hatching after transfer to $30^{\circ} \mathrm{C}$ as diapause. Embryos in the diapause stage (late anatrepsis) require approximately 10 days to complete post-diapause development (Tanaka, 1992; Tanaka and Zhu, 2008). Some egg pods died and those with a rate of mortality higher than $50 \%$ were discarded ( $13.6 \% ; n=14 / 132$ egg pods), because dead eggs often rotted and were difficult to count accurately. The incidence of diapause was arc-sine transformed before being subjected to statistical analyses.

To test the effect of parental photoperiod on the induction of embryonic diapause, hatchlings from eggs deposited by field-collected females were reared in groups of approximately 100 individuals in wood-framed cages $(42 \times 22 \times 42 \mathrm{~cm})$ under a $12 \mathrm{~L} 12 \mathrm{D}, 14 \mathrm{~L} 10 \mathrm{D}$ or $16 \mathrm{~L} 8 \mathrm{D}$ photoperiod and $30^{\circ} \mathrm{C}$. After adult emergence, they were continuously kept under the same photoperiodic conditions and obtained egg pods were individually held with moist sand in plastic cups (volume, $180 \mathrm{ml}$ ) to incubate at $20^{\circ} \mathrm{C}$ in darkness. All egg pods were transferred from 20 to $30^{\circ} \mathrm{C}$ on the 60th day after deposition according to the method of Tanaka and Zhu (2008) and the incidence of diapause was then determined and analyzed as above.

\section{RESULTS}

\section{Body coloration and morphometric characteris- tics}

Adults of L. migratoria were collected from 21 October 2006 to 21 March 2007. A few last-stadium nymphs were observed in October $(1.5 \%$; $n=5 / 345)$ and November $(1.7 \% ; n=3 / 177)$. This species was found together with another more abundant large locusts, the Bombay locust, Nomadacris succincta at all collection sites on Iheya Island. On 16-17 November, adults of L. migratoria were relatively abundant with the highest density of approximately 0.2 per $\mathrm{m}^{2}$, but their number decreased rapidly in December onward and only 11 adults could be collected on 15-16 March after four people searched for $6 \mathrm{~h}$. These observations suggest that adults of L. migratoria overwintered on this island and a high rate of mortality occurred during the winter.

Adults collected during the present census showed a full range of variation in body color. Some adults assumed a greenish or brownish body color (Fig. 2A, B, E and F), whereas others had a brownish body with some black spots on the wings and thorax (Fig. 2C, D, G and H). The upper edge of the pronotum was arched or convex in the former and either flat or concave in the latter. The arched shape of the pronotum is typically observed in solitarious forms and the concave shape in gregarious forms (Uvarov, 1966; Pener, 1991). The frequency of the latter was $7.8 \%$ in females and $9.8 \%$ in males $(n=102$ each). Locust populations on the island had become considerably smaller by autumn 2008, although no quantitative data were collected to compare population sizes between years. The upper edge of the pronotum was convex in all adults collected on September 24-25, $2008(n=26$ and 19 in females and males).

Body dimensions and morphometric ratios of collected adults are summarized in Table 1. Body length, head width, hind femur length, and fore wing length were all significantly larger in females than in males ( $t$-test; $p<0.001$ each). The mean $\mathrm{F} / \mathrm{C}$ ratio was smaller in females than in males (Mann-Whitney's $U$-test; $z=-5.361 ; p<0.001$ ) and the reverse was true for the mean $\mathrm{E} / \mathrm{F}$ ratio (Mann-Whitney's $U$-test; $z=-2.131 ; p<0.05$ ). Individual variation of either ratio was considerably large, as shown in Fig. 3 in which the mean ratios 

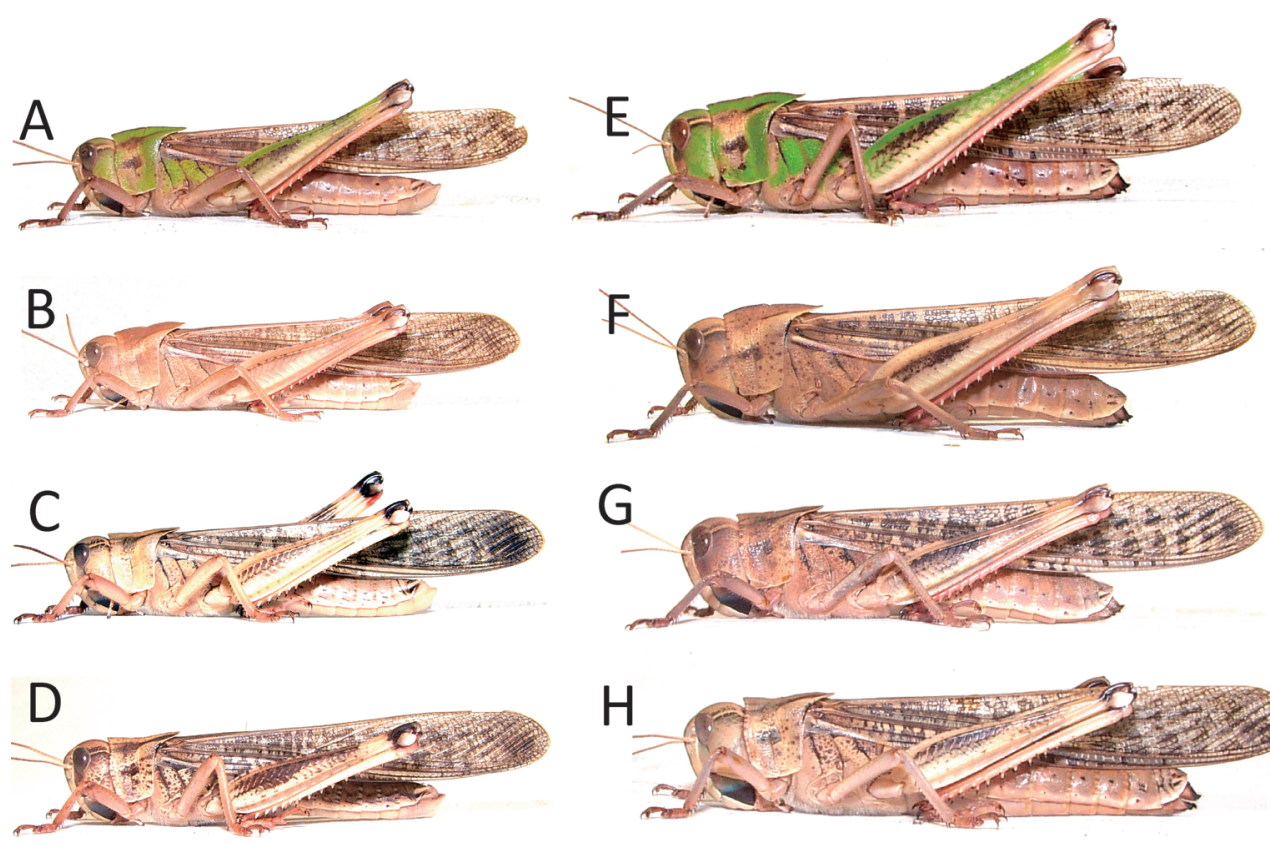

Males

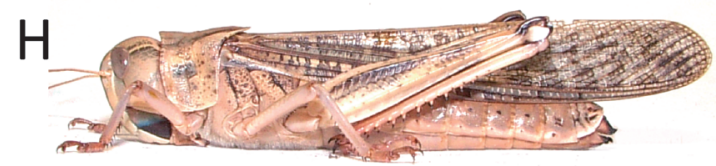

Females

$1 \mathrm{~cm}$

Fig. 2. Adult specimens of L. migratoria collected on Iheya Island on 19 November 2006. A-D, males; E-H, females. Note that the upper edge of pronotum is arched in the upper four specimens (A, B, E and F) and flat or concave in the lower four (C, D and $\mathrm{G}$ and $\mathrm{H}$ ).

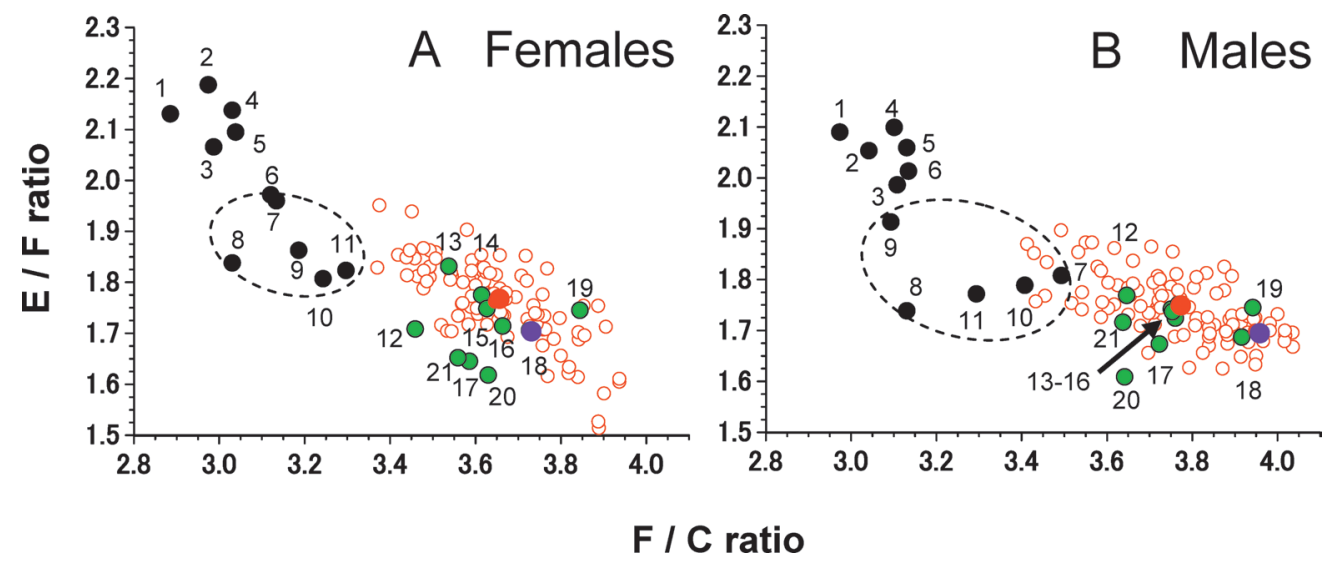

Fig. 3. E/F (fore wing length/hind femur length) ratios plotted against F/C (hind femur length/head width) ratios for $L$. migratoria adults collected on Iheya Island in October and November 2006 ( $\bigcirc$ for individual data; $\bigcirc$ for means) as compared with mean ratios for adults collected on Iheya Island in 2008 ( ) and in other localities at outbreaks (O) and at recession (low density) times (O). Numbers in the figure indicate collection sites: 1, 14, Madagascar; 2, 19, Philippines; 3, 18, Papua New Guinea; 4, 13, Mali; 5, northern China; 6, 15, Australia; 7, 21, Isahaya; 8, Mage Island; 9, Kita-Daito Island; 10, Kansai International Airport; 11, 16, Minami-Daito Island; 12, Central Africa; 17, Amami Ooshima; 20, Kagoshima. Data are based on various sources described in Materials and Methods. Dotted circles indicate the ranges of values for Japanese populations at outbreaks.

recorded at outbreaks and at low population densities in other areas of Japan and other countries are plotted for comparison. For mean values, locusts collected on Iheya Island in 2006 showed morphometric ratios typical of solitarious locusts; however, a few individuals had relatively small $\mathrm{F} / \mathrm{C}$ ratios and large $\mathrm{E} / \mathrm{F}$ ratios often recorded at outbreaks. For example, the mean $\mathrm{F} / \mathrm{C}$ and $\mathrm{E} / \mathrm{F}$ ratios in the swarming populations on Mage Island in 1986 were 3.03 and 1.84 in female adults and 3.14 and 
Table 1. Body dimensions ( $\mathrm{mm}$ ) and morphometric ratios of adult specimens ( $n=102$ for each sex) collected on 21 October 2006

\begin{tabular}{llcccccc}
\hline & MBL & C & F & E & F/C & E/F \\
\hline \multirow{2}{*}{ Females } & Mean & 59.09 & 7.33 & 26.75 & 47.04 & 3.646 & 1.764 \\
& SD & 3.14 & 0.40 & 2.11 & 2.24 & 0.133 & 0.079 \\
& Maximum & 66.8 & 8.5 & 32.3 & 53.6 & 3.937 & 1.951 \\
& Minimum & 45.4 & 6.5 & 23.3 & 41.0 & 3.370 & 1.514 \\
& & & & & & & \\
Males & Mean & 48.72 & 5.89 & 22.14 & 38.69 & 3.764 & 1.749 \\
& SD & 2.32 & 0.28 & 1.03 & 1.60 & 0.152 & 0.060 \\
& Maximum & 57.2 & 6.7 & 24.9 & 41.8 & 4.036 & 1.897 \\
& Minimum & 41.8 & 5.3 & 20.0 & 35.1 & 3.413 & 1.625 \\
& $p$ & $<0.001^{\mathrm{a}}$ & $<0.001^{\mathrm{a}}$ & $<0.001^{\mathrm{a}}$ & $<0.001^{\mathrm{a}}$ & $<0.001^{\mathrm{b}}$ & $<0.05^{\mathrm{b}}$ \\
\hline
\end{tabular}

MBL, C, F and E represent maximum body length from the head to the tip of wings, maximum head width, hind femur length and fore wing length.

${ }^{\mathrm{a}} t$-test. ${ }^{\mathrm{b}}$ Mann-Whitney $U$-test.

1.74 in male adults (No. 8 in Fig. 3A and B). Similar values were also reached by adults of the Kitaand Minami-Daito Island populations in 19731974 (No. 9, 11 in Fig. 3A and B; Ito and Yamagishi, 1976), those of the Isahaya population in 2000 after land reclamation was started in Isahaya Bay (No. 7 in Fig. 3A and B; Y. Ikezaki and S. Tanaka, unpublished observations) and those from Kansai International Airport in 2007 when a new runway was completed (No. 10 in Fig. 3A and B; S. Tanaka, K. Maeno and M. Takeda, unpublished observations). These results indicate that some individuals of the Iheya Island population probably experienced crowding as nymphs, although most were probably grown at a low population density. Adults collected on September 24-25, 2008 had both $\mathrm{F} / \mathrm{C}$ and $\mathrm{E} / \mathrm{F}$ values more typical of solitarious forms than those collected in 2006 (Fig. 3A and $\mathrm{B}) . \mathrm{F} / \mathrm{C}$ and $\mathrm{E} / \mathrm{F}$ ratios in the former $(3.729 \pm 0.077$ and $1.706 \pm 0.055$ in females, $n=26 ; 3.946 \pm 0.128$ and $1.701 \pm 0.012$ in males, $n=19$ ) were significantly different from those in the latter (Table 1; Mann-Whitney's $U$-test; $p<0.05$ each).

\section{Ovarian development during the winter and mating activity}

Figure 4 illustrates the seasonal changes in oocyte length in adults of L. migratoria collected on Iheya Island. Mean oocyte length was approximately $1 \mathrm{~mm}$ in October and November, slightly increased in December and January, and rapidly increased in February. Figure 5 shows the distribu-

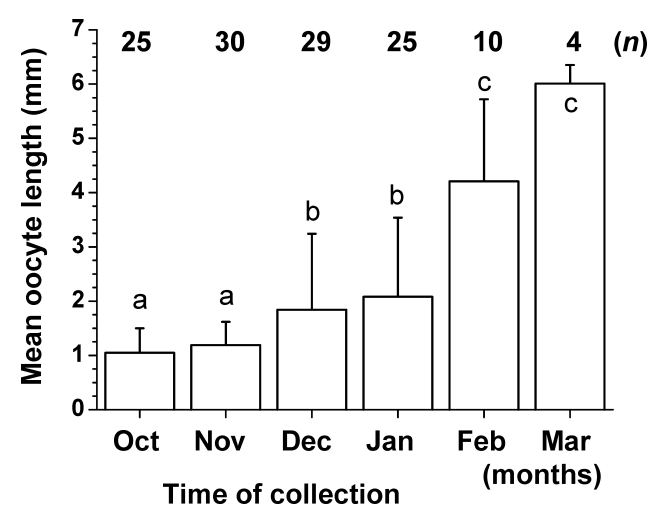

Fig. 4. Mean oocyte lengths $( \pm \mathrm{SD})$ of L. migratoria adults collected on Iheya Island from October 2006 to March 2007. Different letters in the figure indicate significant differences at 5\% (Scheffé's test).

tion of individual females with various lengths of oocytes in each sample. Three stages of oocyte development may be recognized: oocytes in stage I remained less than $1.6 \mathrm{~mm}$ in length, those in stage II developed rapidly with their length ranging from $1.6 \mathrm{~mm}$ to ca. $6 \mathrm{~mm}$ before chorionation, and those in stage III were chorionated and ca. $6 \mathrm{~mm}$ or longer. The proportion of developing and mature oocytes was less than $10 \%$ in October and November, started increasing in December and peaked in March, showing the same pattern of changes as observed for ovarian development indicated by mean oocyte length; however, it should be noted that all samples had some individuals with developing or mature oocytes. Mature oocytes or eggs were found in females collected in March, which sug- 


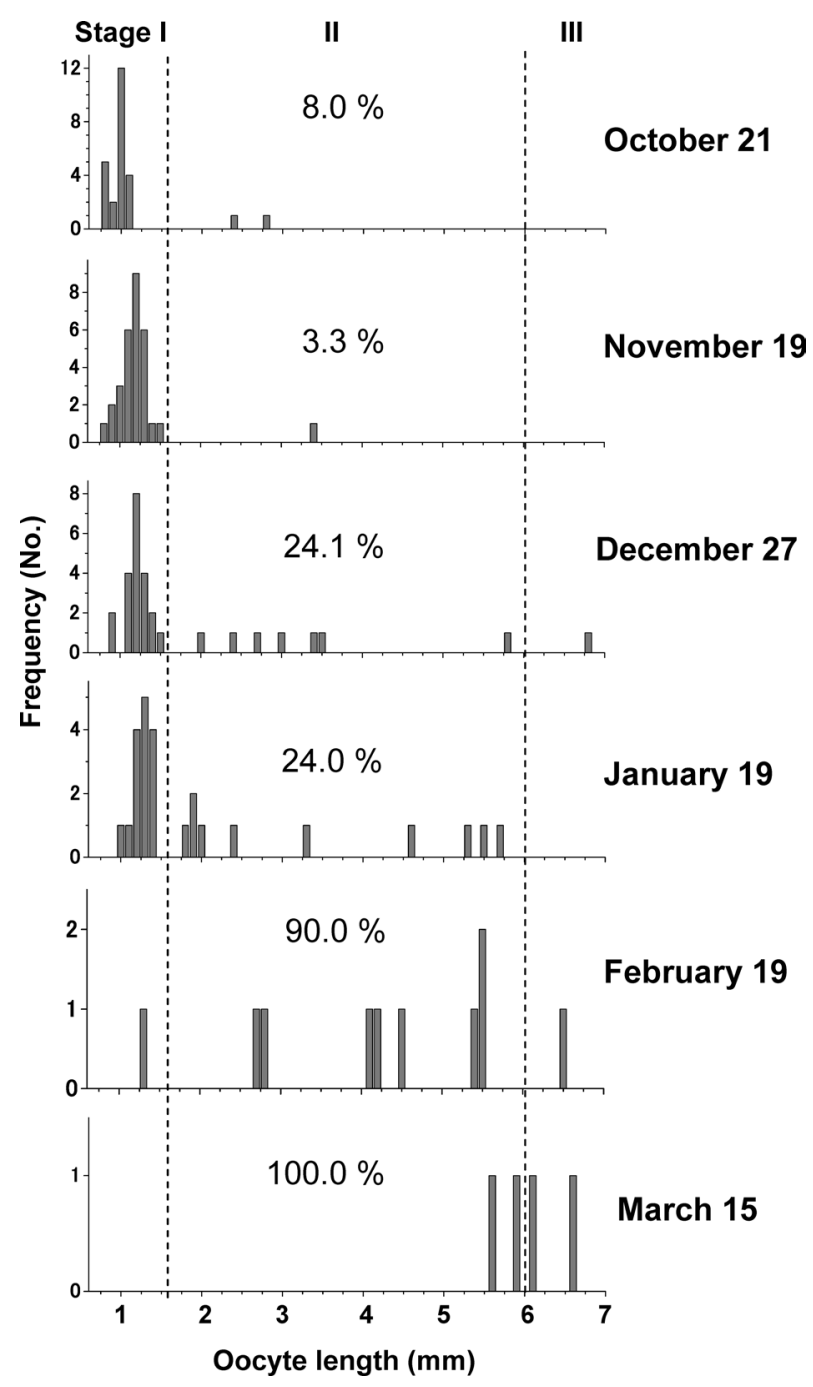

Fig. 5. The frequency distribution of mean oocyte lengths in L. migraotria adults collected on Iheya Island on different dates from 21 October 2006 to 15 March 2007. Ovarioles were divided into three developmental stages divided by dotted lines: stage 1, small oocytes; stage 2 , developing oocytes before chorionation; stage 3 , mature chorionated oocytes. Numbers in panels indicate the proportion of females with developing and mature oocytes.

gested that oviposition started around that time.

\section{Pre-ovipositional period}

The time required to start ovipositing at $30^{\circ} \mathrm{C}$ and a $12 \mathrm{~L} 12 \mathrm{D}$ photoperiod (pre-ovipositional period) was determined for individual female adults collected in the field (Fig. 6). Female locusts collected on October 21 took 9-21 days to start ovipositing with a mean value of 16.4 days $(n=29)$. Those collected on 19 November showed a wider range of pre-ovipositional period, 9-35 days, and

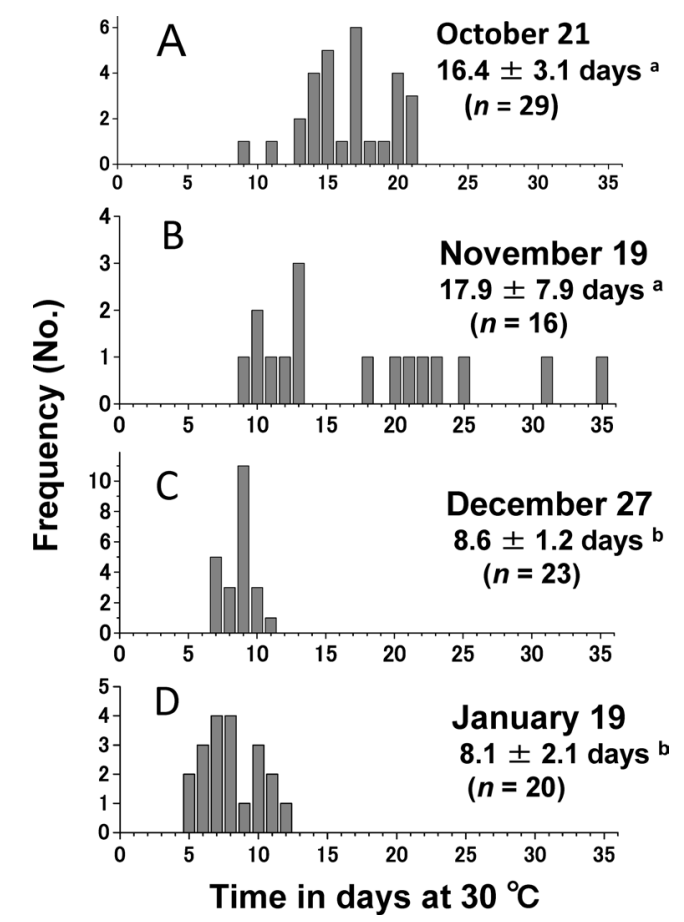

Fig. 6. Frequency distribution of pre-ovipositional periods in L. migratoria adults collected on different dates on Iheya Island. Means \pm SD are given with sample sizes in parentheses. Different letters after the mean values indicate significant differences at 5\% (Scheffé's test).

the overall mean (17.9 days; $n=16$ ) was not significantly different from the value in the October sample $(t$-test; $p>0.05)$. It appeared that the November sample consisted of two groups of females; oviposition started rapidly in one group (range, 9-13 days; mean $\pm \mathrm{SD}=11.4 \pm 1.6$ days; $n=8$ ) and slowly in the other (range, 18-35 days; mean $\pm \mathrm{SD}=24.4 \pm$ 5.8 days; $n=8$ ). The mean values of the two groups were different significantly not only from each other but also from the value of the October sample (Scheffe's test after ANOVA; $p<0.05$ ). Oviposition started rapidly and simultaneously in females collected in December and January (Fig. 6C and D). The mean pre-ovipostional period tended to decrease as the season advanced.

The mean number $( \pm \mathrm{SD})$ of eggs per egg pod was 44.3 ( \pm 12.8 eggs; range, $12-66 ; n=114)$. This and the mean number of ovarioles per ovary $(100.9 \pm$ 7.5 ; range, $86-120 ; n=105$ ) indicated that females used $43.9 \%$ of ovarioles to produce eggs on average (44.3 eggs/100.9 ovarioles).

A few mating or mounting pairs were seen in field populations in December and January when 
the population sizes were still relatively large. Interestingly, mounting pairs were observed in cages in which collected locusts were temporarily held before shipment each time. In the laboratory, mounting and mating behavior was seen at least in some pairs at $30^{\circ} \mathrm{C}$ and a $12 \mathrm{~L} 12 \mathrm{D}$ within 1 or 2 days after each collection.

\section{Seasonal changes in propensity to enter dia- pause}

Egg pods deposited by field-collected females under a $12 \mathrm{~L} 12 \mathrm{D}$ photoperiod and $30^{\circ} \mathrm{C}$ were incubated at $20^{\circ} \mathrm{C}$ to determine the incidence of diapause eggs in each egg pod. Figure 7 plots the mean incidences of diapause eggs at 10-day intervals against the date of oviposition. This incidence of diapause was considerably high in egg pods produced in November, decreased in December and reached a minimum level in February. A significant negative correlation was found between the incidences of diapause and the time of oviposition $(R=-0.798 ; z=-11.526 ; p<0.001 ; n=114)$.

\section{Photoperiodic control of embryonic diapause}

The incidence of egg diapause was examined at $20^{\circ} \mathrm{C}$ for egg pods produced by locusts reared under three different photoperiods. The parental photoperiod influenced the incidence of embryonic diapause (ANOVA; $F=14.204 ; \mathrm{df}=2,90 ; p<$ 0.001; Fig. 8). Locusts reared under a 12L12D photoperiod produced $27.8 \%$ of diapause eggs on average, whereas those reared under a longer photoperiod produced a significantly smaller incidence (Scheffe's test; $p<0.05$ ). It should be noted that inter-pod variation is considerably large even under the shortest photoperiod, as indicated by the large SD (34.2).

\section{DISCUSSION}

\section{Morphological characteristics of locusts after outbreaks}

As far as the mean values of morphometric ratios are concerned, the populations of L. migratoria on Iheya Island in autumn 2006 may be regarded as the solitarious phase; however, a small proportion of adults had some characteristics typically observed in locust populations of outbreaks in Japan. The latter include those on Kita- and MinamiDaito Islands in 1973-1974 (Ito and Yamagishi,

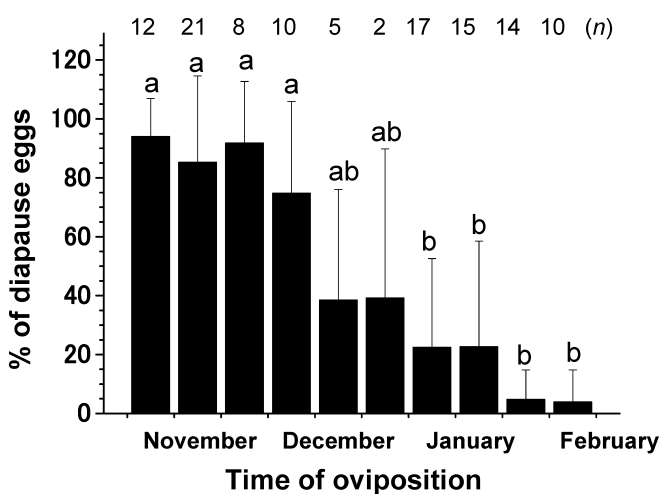

Fig. 7. The mean incidence of diapause eggs in egg pods laid by field-collected L. migratoria female in each 10-day period under a $12 \mathrm{~L} 12 \mathrm{D}$ photoperiod and $30^{\circ} \mathrm{C}$ and incubated at $20^{\circ} \mathrm{C}$. Analysis was based on first and third egg pods produced by each female. Vertical bars indicate SD. Different letters near histograms indicate significant differences at 5\% (Scheffe's test after arcsine transformation of the data).

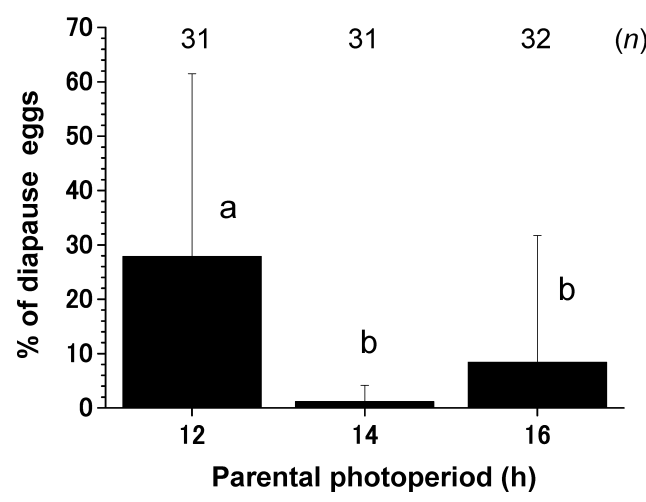

Fig. 8. The mean incidence of diapause in egg pods laid by L. migratoria locusts reared in groups of about 100 individuals at different photoperiods and $30^{\circ} \mathrm{C}$ as nymphs and adults. All eggs were incubated at $20^{\circ} \mathrm{C}$. Vertical bars indicate SD. Different letters near histograms indicate significant differences at 5\% (Scheffé's test after arcsine transformation of the data).

1976), on Mage Island in 1986 (Tanaka, 1987), on Isahaya Bay reclaimed land in 2000 (Y. Ikezaki and S. Tanaka, unpublished data) and at Kansai International Airport in 2007 (S. Tanaka, K. Maeno and M. Takeda, unpublished observations). In those populations (in dotted circles in Fig. 3A and B), the mean $\mathrm{F} / \mathrm{C}$ ratio ranged from 3.03 to 3.30 in females and from 3.09 to 3.49 in males, while the E/F ratio ranged from 1.84 to 1.96 in females and from 1.74 to 1.91 in males. These values are between the ratios typically observed for solitarious and gregarious forms. This, together with their dark body coloration and black spots on the thorax and a con- 
cave pronotum, may indicate that individuals with relatively small $\mathrm{F} / \mathrm{C}$ ratios and large $\mathrm{E} / \mathrm{F}$ ratios experienced crowded conditions as nymphs on Iheya Island before they were sampled. A rapid change in morphometric ratios toward those typical of solitarious locusts was recorded for Mage Island populations after outbreaks. According to unpublished observations by A. Tanaka (unpublished observations), the mean $\mathrm{F} / \mathrm{C}$ ratio for Mage Island populations, which was 3.03 and 3.13 in females and males in October 1986 (Tanaka, 1987), had increased to 3.40 and 3.57, respectively, by August 1987 ( $n=10$ in females and 20 in males). The latter values were only slightly lower than those recorded for solitarious individuals in the same prefecture (3.63 and 3.64 in females and males, respectively; No. 20 in Fig. 3; Tanaka, 1987). A similar phenomenon was also observed with the Iheya Island population in the present study. The morphometric ratios, which had already been within the range of solitarious forms in 2006, had shifted further to values more typical of solitarious locusts (larger $\mathrm{F} / \mathrm{C}$ and smaller E/F ratios) by autumn 2008 .

\section{Overwintering biology}

The locust populations on Iheya Island mainly consisted of adults in late October. The locusts were relatively abundant and more than 300 adults could be caught by four people within $70 \mathrm{~min}$ at night. The population density was still high enough to collect about 180 adults in $8 \mathrm{~h}$ in late November, but it became more and more difficult to find locusts after December and only 11 individuals could be collected in March. The cause of this apparent reduction in population size is not clear. At the end of the outbreaks on Mage Island, many locusts infected by Entomophaga grylli were found dead on vegetation and the population size declined markedly thereafter (Tanaka and Kiritani, 1987). They were characteristically found clinging to plants, and a similar scene was seen at Kansai International Airport in 2007 (S. Tanaka, K. Maeno and M. Takeda, unpublished observations). During the present study, no such individuals of L. migratoria were observed on Iheya Island, although a few dead bodies of $N$. succincta were found clinging to silver grass stalks.

There is no doubt that L. migratoria overwinter as adults on Iheya Island. The present study indicated that most adults collected in October were re- productively inactive with small ovarioles. When kept at a $12 \mathrm{~L} 12 \mathrm{D}$ photoperiod and $30^{\circ} \mathrm{C}$, they took about 16 days to start laying eggs on average. Adults collected one month later and treated in the same way showed two distinct groups: one group started oviposition earlier than the other (Fig. 6). Compared with the mean pre-ovipositional period in the October sample, the former had a significantly shortened pre-ovipositional period, whereas the latter had delayed oviposition. The factor causing this delay is not clear, but it is possible that adult locusts control the rate of sexual maturation in response to day length and temperature. The photoperiodic control of sexual maturation is known for a temperate population of this locust (Tanaka et al., 1993; Hasegawa and Tanaka, 1996). The pre-ovipositional period after transfer to the laboratory decreased gradually over the time of collection in the present study, and adults collected in late January took only 8 days to start oviposition on average. Unfortunately, it was not possible to determine the pre-ovipositional period in February and March, because of difficulty in obtaining enough locusts. From the gradual reduction of the pre-ovipositional period with the time of collection (Fig. 6), however, it may be safe to infer by extrapolation that adults would start laying eggs in March or later. This inference is consistent with the results of dissection that all females collected on 15 March had well-developed ovaries, some of which contained chorionated oocytes (Fig. 5).

A few mounting or mating pairs were seen in the field in December or January; however, at least some males were apparently ready to mate at any time in the field populations, because mating was always observed in some locusts within one hour after they were collected and place in cages in the field. It seems that handling triggered mating behavior in those locusts that would otherwise have remained without mating, at least for a while. Because this locust displays multiple mating, it is probably not advantageous for males to mate with reproductively immature females. In fact, sperm precedence by the last male to mate is known to be relatively high under either isolated (solitarious) or crowded (gregarious) conditions (Zhu and Tanaka, 2002; Tanaka and Zhu, 2003).

Dissections of field-collected females revealed another aspect of the winter biology of L. migratoria on Iheya Island. Although the majority of fe- 
males had relatively small oocytes, females with developing oocytes or mature oocytes were present in small numbers throughout the winter. This suggests that oviposition as well as mating may take place in a small number of individuals even during the winter.

Eggs produced by field-collected females in the laboratory (12L12D photoperiod and $30^{\circ} \mathrm{C}$, Fig. 8) developed rapidly without entering diapause when incubated at high temperatures, such as 25 and $30^{\circ} \mathrm{C}$, but entered diapause at a low incubation temperature of $20^{\circ} \mathrm{C}$. This is a typical response observed in subtropical and tropical populations of L. migratoria (Tanaka, S., 1994; Tanaka and Zhu, 2008), and may suggest that eggs produced in the autumn and winter would enter diapause on Iheya Island where the air temperature stays below $20^{\circ} \mathrm{C}$ during the winter months.

The incidence of diapause eggs at $20^{\circ} \mathrm{C}$ was more than $80 \%$ in those deposited in November by October females, gradually decreased over the time of collection of adults, and declined to below 5\% in eggs produced by locusts collected in January. Rearing experiments indicated that the incidence of diapause is significantly higher under a short photoperiod than a long photoperiod; however, the mean incidence of diapause eggs was less than $30 \%$ even under the shortest photoperiod (12L12D) tested. It may be argued that a 12L12D photoperiod is still too long to induce a high incidence of diapause in this population, because day length becomes shorter than a 12L12D photoperiod at the winter solstice at this latitude (Beck, 1980). This possibility should be tested in the future; however, it does not explain why adults collected near the winter solstice produced egg pods with reduced incidences of egg diapause (ca. 23\% in egg pods produced in January by females collected in late December; Fig. 7). In a temperate population of this species, a change in photoperiod at adult emergence influences the induction of diapause (Tanaka and Zhu, 2008). It is possible that seasonal changes in photoperiod as well as temperature play some role in the control of egg diapause in this population.

\section{Seasonal life cycle on Iheya Island}

The L. migratoria population on Iheya Island and nearby subtropical islands may produce 3 or more generations per year (Tanaka, S., 1994). The present study suggested that this population does not have a fixed, but a variable life cycle. This phenomenon is probably related to two characteristics: (1) this species has no apparent mechanism to control nymphal development seasonally (Hakomori and Tanaka, 1992; Tanaka, H., 1994) and (2) the Iheya population overwinters at any developmental stages including egg, adult and perhaps nymphal stages under relatively mild conditions. In fact, both adults and last stadium nymphs overwinter in the northern part of Okinawa Main Island, one of the closest islands to this island (Tanaka, S., 1994). It may be expected that these two characteristics could lead to the pattern of a homodynamic life cycle in which development depends simply on the ambient temperature without any special seasonal control, as exemplified by several species of tropical crickets (Masaki and Walker, 1987); however, the locust population on Iheya Island does not show such a pattern. As mentioned above, autumn adults seem to have some mechanism to delay the time of sexual maturation until the second half of winter, and eggs have the capacity for diapause, the induction of which is apparently controlled seasonally. The latter may ensure that reproductively active female adults occurring in the autumn produce eggs overwintering as diapause eggs and those occurring in the winter tend to produce eggs without diapause. The majority of overwintering adults may start oviposition in March and continue to produce eggs until April or May. Their eggs would hatch later than those deposited in the previous autumn or winter, but all these eggs would hatch in the spring; therefore, the developmental responses controlling sexual maturation and egg diapause appear to work in such a way that, irrespective of the overwintering stages, egg hatching is prevented from occurring in the winter. It is possible that the chance of survival in hatchlings or early stadium nymphs during the winter is considerably low on this island and that this low rate of survival might have served as a driving force to shape the life-history characteristics of this locust on this island. At present, no empirical data are available to evaluate this hypothesis, but the present study suggests that overwintering at different developmental stages does not necessarily indicate the absence of seasonal control of the life cycle. 


\section{ACKNOWLEDGEMENTS}

Ms. Chie Moromizato (Hokubu Agriculture, Forestry and Fisheries Promotion Center of Okinawa Prefecture) and $\mathrm{Mr}$. Shinya Saito (Iheya Island Fishermen's Union, Okinawa) provided us with valuable information about locusts and kind accommodation on Iheya Island. Many thanks are due to Ms. Chieko Ito, Ms. Hiroko Ikeda and Ms. Masako Higuchi (NIASO) for laboratory assistance and to Dr. Koutaro Maeno, Dr. Makoto Tokuda, Dr. Mika Murata and Dr. Ken-ichi Harano (NIASO) for stimulating discussions and valuable comments on the manuscript. We thank Dr. Akira Tanaka (Bayer CropScience, Japan) for sending us literature and unpublished data of locusts on Mage Island, Prof. Yoshihiro Ikezaki (Nagasaki Women's Junior College, Japan) for supplying S.T. specimens collected in 2000 from Isahaya Bay reclaimed land for morphometric analysis, and Mr. Ken-ichi Kanai (Ooshima High School) for collecting locusts for us on Amami Ooshima. The Phase Two Facilities Development Department of Kansai International Airport not only kindly sent sprayed specimens to S.T., but also allowed him and his colleagues to investigate the locust populations at the new runway before opening when outbreaks occurred in 2007. The grass used for rearing was raised by the Field Management Section of NIASO. The research was partly supported by Kakenhi funds of Japan to S.T.

\section{REFERENCES}

Beck, S. D. (1980) Insect Photoperiodism. 2nd ed. Academic Press, New York. 387 pp.

Dirsh, V. M. (1953) Morphometrical studies on phases of the desert locust (Schistocerca gregaria Forskål). Anti-Locust Bull. 16: 1-34.

Farrow, R. A. and D. H. Colless (1980) Analysis of the interrelationships of geographical races of Locusta migratoria (Linnaeus) (Orthoptera: Acrididae), by numerical taxonomy, with special reference to sub-speciation in the tropics and affinities of the Australian race. Acrida 9: 77-99.

Hakomori, T. and S. Tanaka (1992) Genetic control of diapause and other developmental traits in Japanese strains of the migratory locust, Locusta migratoria L.: univoltine vs. bivoltine. Jpn. J. Entomol. 60: 319-328.

Hasegawa, E. and S. Tanaka (1996) Sexual maturation in Locusta migratoria females: laboratory vs. field conditions. Appl. Entomol. Zool. 31: 279-290.

Ito, Y. and M. Yamagishi (1976) Outbreaks and partial phase transformation of Locusta migratoria L. in sugarcane fields of Minami- and Kita-Daito Zima, Okinawa. Acrida 5: 17-26.

Lecoq, M. (2005) Desert locust management: from ecology to anthropology. J. Orthop. Res. 14: 179-186.

Masaki, S. and T. J. Walker (1987) Cricket life cycles. Evol. Biol. 31: 349-423.

Pener, M. P. (1991) Locust phase polymorphism and its endocrine relations. Adv. Insect Physiol. 23: 1-79.

Tanaka, A. (1987) A report on emergency measures against agricultural pests undergoing outbreaks [Tahassei kinkyu byougaichu taisaku seisekisho]. Bull. Kagoshima Pref. Exp. Stn. 6: 1-30 (in Japanese).

Tanaka, A. and K. Kiritani (1987) An outbreak of Locusta migratoria manilensis on Magesima Island, II: End of the outbreak. Insectarium 24: 330-337 (in Japanese).

Tanaka, H. (1994) Geographic variation of embryonic diapause in the migratory locust, Locusta migratoria (Orthoptera: Acrididae), in Japan. Jpn. J. Entomol. 62: 629-639.

Tanaka, S. (1992) The significance of embryonic diapause in a Japanese strain of the migratory locust, Locusta migratoria (Orthoptera: Acrididae). Jpn. J. Entomol. 60: 503-520.

Tanaka, S. (1994) Diapause as a pivotal factor for latitudinal and seasonal adaptation in Locusta migratoria in Japan. In Insect Life-cycle Polymorphism (H. D. Danks, ed.). Kluwer Academic Publishers, London, pp. 173-190.

Tanaka, S. and D.-H. Zhu (2003) Phase-related differences in mating strategy of a locust. Ann. Entomol. Soc. Am. 96: 498-502.

Tanaka, S. and D.-H. Zhu (2005) Outbreaks of the migratory locust Locusta migratoria (Orthoptera: Acrididae) and control in China. Appl. Entomol. Zool. 40: 257-263.

Tanaka, S. and D.-H. Zhu (2008) Geographic variation of embryonic diapause, cold hardiness and life cycles in the migratory locust Locusta migratoria (Orthoptera: Acrididae) in China. Entomol. Sci. 11: 371-383.

Tanaka, S., T. Hakomori and E. Hasegawa (1993) Effects of daylength and hopper density on reproductive traits in a Japanese population of the migratory locust, Locusta migratoria L. J. Insect Physiol. 39: 571-580.

Uvarov, B. (1966) Grasshoppers and Locusts. Vol. 1. Cambridge University Press, London. 481 pp.

Zhu, D.-H. and S. Tanaka (2002) Prolonged precopulatory mounting increases the length of copulation and sperm precedence in Locusta migratoria (Orthoptera, Acrididae). Ann. Entomol. Soc. Am. 95: 370-373. 